\title{
How Costly Are Smokers to Other People? Longitudinal Evidence on the Near Elderly
}

Gabriel Picone, University of South Florida

Frank Sloan, Duke University and NBER

\section{Executive Summary}

Many studies have estimated the cost of smoking. In recent years, such estimates have been widely used in litigation against the tobacco companies. Both longitudinal and cross-sectional methods have been used. On balance, the longitudinal approach, the one used in this study, is much preferable since one can account for the effects of smoking on the pool of eligibles rather than just conditioning expenditures on being eligible. We used data from four waves of the Health and Retirement Study to assess the impact of smoking on use of hospital and physicians' services and nursing home care. The analysis was limited to utilization among persons aged 51 to 67 ("near elderly"). During this phase of the life cycle, many adverse effects of smoking, measured in terms of mortality and morbidity, first occur. In contrast to past studies, we computed the health expenditure burden of smoking by type of health insurer. The net effect of smoking on expenditures on health care services was positive for this age cohort. We found substantial differences in the burden that smoking imposes on various payers. The largest impact was on other government payers, which includes the Veterans Administration, followed by the effects on Medicare and Medicaid. By contrast, the effects of smoking on private insurers' cost were negligible.

\section{Introduction}

Cigarette smoking is the largest single source of preventable mortality and morbidity in the United States (Bartecchi et al. 1994). In 1990, for example, about one-fifth of all deaths are attributable to smoking (MMWR 1993). Effects on morbidity, especially on certain types of cancer, heart disease, stroke, and nonmalignant lung disease, have been documented (Peto 1994).

Several negative externalities are attributable to cigarette smoking and provide the rationale for various forms of public regulation of 
cigarettes. One type of externality is financial. Because of various forms of insurance, including public health insurance coverage, private group health insurance, public disability coverage, and public annuities in the form of Social Security benefits, smokers may not pay for the total cost of harm they cause. Second, environmental smoke may cause harm to others. Some deleterious effects of environmental smoke on birth-weight and incidence of cancer have been documented, although as with the first externality, there is ongoing debate about magnitudes of effect (Manning et al. 1989; U.S. Environmental Protection Agency 1994). In addition, there is the annoyance experienced by nonsmokers in smoky environments, but this cost has not been quantified. Third, cigarette smoking is highly addictive and the habit is almost always acquired during childhood (see, for example, U.S. Department of Health and Human Services 2000, p. 121). Under the doctrine of consumer sovereignty, private consumption decisions are ordinarily considered to be an internal matter and certainly not a source of external costs. In view of the young age at which this form of addiction is acquired, however, it seems difficult to presume that these are informed judgments by rational actors, or that the parents of youths would make decisions consistent with those of their children. In this sense, actions by tobacco manufacturers to make their products more attractive to youths may be considered to have external costs, providing still another reason for public regulation. In fact, one group of economists concluded that these actions by tobacco manufacturers are on balance, the strongest rationale for such regulation of the three sources of negative externalities (Warner et al. 1995).

Public regulation of cigarette smoking takes many forms: excise taxes on cigarettes, restricted availability of cigarettes at the point of sales, bans restricting where smoking can occur (e.g., in restaurants, and public buildings), cigarette advertising bans, and imposition of tort liability on cigarette manufacturers for prior harm caused by smoking (Hanson and Logue 1998; Jacobson and Warner 1999). Plaintiffs' success in litigation against tobacco companies is relatively recent; that is, this success has taken place since 1992 (Rabin 1993). Probably the most notable success is the settlement between some tobacco manufacturers and forty-six state attorneys general reached in November 1998. This settlement provided for major indemnity payments by manufacturers as well as an agreement to abide by various restraints on their behavior, such as in advertising. 
An important characteristic of smoking is the long latency period between time of initiation and the onset of adverse effects. Relatively few adverse health effects occur before a late age. To illustrate, at age 35 , the cumulative probability of survival is the same for those who have never smoked and smokers. At age 45, the ratio of such probabilities, those who have never smoked to smokers, is 1.02 for males and 1.00 for females. At age 55, the corresponding ratios are 1.06 for males and 1.02 for females, and at age 65 , the ratios are 1.18 and 1.08. By age 85 , the ratios are 2.11 for males and 1.57 for females (Hodgson 1992, p. 91). Excess morbidity and consequent elevated cost occurs earlier, however, for some smoking-related diseases such as lung cancer; the lag between initial treatment and death is less than a year on average (Fry et al. 1999; Ramalingam et al. 1998).

Harm from smoking and the various public interventions to deal with it are vast topics. The objectives of this study are far more limited-to assess the costs of smoking measured in terms of spending on personal health care services for a defined age group of individuals, persons aged 51 to 67 , and to estimate the incidence of such costs by source of payment for health expenditures. Our primary data source for this study is the first four waves of the Health and Retirement Study (HRS). This national survey interviewed persons aged 51 to 61 in 1992 and their spouses who could be of any age. By the fourth wave, which was conducted in 1998, the 61-year-olds were 67.

Our analytical approach represents an improvement over past cost of smoking studies in the following respects. First, unlike most cost of smoking studies, especially those done in the United States (Warner et al. 1999), we used a life-cycle approach. We explain the advantages of this approach below. Second, the HRS provides longitudinal data on survival, source of payment for health services, and health services use. Having data on many relevant covariates allowed for development of a more accurate life table than has been available previously. Smokers differ from nonsmokers in many other respects. In this study, we were able to observe types of heterogeneity not often measured in past work, e.g., risk preferences (Hersch and Viscusi 1990). Third, since the HRS provides data on source of payment, we were able to distribute the cost burden of smoking across payers. No study, to our knowledge, has explicitly considered the effects of smoking on payer status, nor has one explicitly incorporated this information in analysis of the cost burden of smoking. Since smoking decreases health, which in turn influences 
employment status and income and payer status (which in the United States is employment-related), this issue is an important adjustment to perform. Fourth, in previous work, it has not been possible to incorporate changes in smoking status and their effects. In fact, during middle age, cessation is quite common, and this change should affect the trajectory of health care cost. Fifth, unlike most studies, we did not limit our analysis to smoking-related diseases. Smoking causes other disease than the major "smoking-related" diseases. Also, it affects the course of recovery from various diseases, regardless of whether or not the diseases are "smoking related." The effect of smoking on recovery is complex and does not always work to the disadvantage of smokers (see, for example, Hasdai et al. 1999).

Our estimates of the increased cost of smoking overall are in line with estimates from previous studies, especially for the United States. However, we found appreciable differences in the burden of smoking cost borne by different health insurers. Thus, if the policy goal is to compensate for losses incurred as a consequence of smoking, adjustment by payer status is critical for aligning costs incurred with compensatory payments from tobacco companies.

In Section II, we discuss some conceptual issues in measuring the cost of smoking. Section III reviews the previous literature on smoking cost. Section IV describes our methodology. In Section V, we present our findings. Section VI places the findings in a larger context and concludes the study.

\section{Conceptual Issues}

\section{Choosing the Right Analytical Approach: Life-Cycle Versus Cross-Sectional Analysis}

The cost of personal health services attributable to smoking can be measured over the life cycle of the smoker or for a single period, such as a year. Higher medical care use and higher mortality attributable to smoking have opposite impacts on lifetime expenditures. Higher medical care use increases lifetime expenditures associated with smoking. Offsetting this increase, at least in part, is the decrease in survival of smokers relative to nonsmokers. Medical care use patterns of smokers and nonsmokers are affected by the various demand determinants, including health status, price of health services, state of the underlying technology for diagnosing and treating disease, care standards, and 
other factors. None of these factors can be known with any degree of certainty at the time smoking is initiated. Both mortality and cost per year are partly affected by cessation, which occurs throughout the life cycle and, for many individuals, only occurs after a health shock has been experienced (Ho 1998; Jones 1996; Wray et al. 1998).

During any year, persons who are alive and smoking are potentially subject to higher expenditures on health care. Most individuals survive the year, but those near death experience elevated health care expenditures on average (Lubitz and Riley 1993).

In the life-cycle approach (sometimes called the "incidence approach"), analytically, one needs to document inflows-insurance premiums and excise taxes-and outflows-excess expenditures on personal health services. These cash flows are brought to present value at some base year, say, when the person is a teenager, by discounting. Premiums do not vary by smoking status. Neither private group insurers nor Medicare varies contributions on this basis. The extent to which individual insurers vary premiums is unknown. Outflows, both those borne by individuals out-of-pocket and others, vary systematically by smoking status.

In analyzing a particular cross-section (sometimes called the "prevalence approach"), the researcher typically finds a smoking-attributable fraction (SAF), that is, the increase in expenditures on personal health services attributable to smoking. Typically, in obtaining the SAF, explanatory variables other than those for smoking behavior are included to control for other determinants of spending. The SAF is then applied to other data on expenditures, such as for Medicaid in a given state in a particular year, to derive the cost of smoking to that payer.

The cross-sectional approach has one major advantage. It is simpler to implement because, to obtain the SAF, one needs only a single cross-section on individuals with data on expenditures and determinants of such expenditures, including smoking behavior. The SAF is then readily applied to publicly available data bases from insurers.

The cross-sectional approach, however, has one important flaw. Outlays from a payer, for example, Medicaid, depend on the number of enrollees and outlays per enrollee. To the extent that smoking results in premature deaths of persons who would otherwise have been enrollees, expenditures are correspondingly diminished. Also, even for persons who survive, persons change insurers. The cost of smoking may have more to do with numbers of people enrolled in a particular program than with spending attributable to smoking, conditional 
on the number of persons covered by the program. The life-cycle method conceptually links the cause (smoking) with the effect (future medical expense) much more directly (see, for example, Miller et al. 1997).

From the standpoint of setting the charge on potential insurers to achieve optimal deterrence by some form of ex ante regulation, including imposing excise taxes on cigarettes, the life-cycle approach is preferable. This approach allows one to identify the cash flows associated with another person starting the habit and the cash flows from quitting or continuing to smoke but reducing one's level of cigarette consumption. One can compute the benefit from a particular action to discourage initiation and encourage cessation, which certainly has consequences over several years, and set cigarette excise taxes, adjust insurance premiums, or impose penalties per smoker on manufacturers according to the quantitative estimates of harm attributable to the activity.

\section{Risk Classification}

For purposes of developing an actuarially fair premium to reflect the added external cost of smoking, it is necessary to answer the counterfactual question: What cost would a nonsmoking person with smoker-like characteristics impose? For purposes of establishing an actuarially fair premium for insurance purposes, just knowing that the person is a smoker or not might be sufficient to achieve some characteristics of an optimal risk classification system, such as separation in expected loss (see Abraham 1986), but risk classes should also provide loss prevention incentives. To craft an adequate disincentive to smoke, one must reward but not under- or overreward such behavior. Demographic characteristics affect medical spending levels and are correlated with smoking. To the extent that smokers differ on demographic characteristics that are clearly exogenous to the smoking decision, adjustment is straightforward. Also, individual tastes, for example, risk preferences, may not be affected by smoking status.

On the other hand, how other health behaviors, such as diet, exercise, and alcohol use, are properly treated in the analysis is more controversial. Such activities may be complements or substitutes for smoking: complements if persons who smoke are also inactive, perhaps due to shortness of breath, or are more likely to consume excess 
amounts of alcohol; substitutes if reductions in smoking lead to offsetting increases in other unhealthy behaviors. One should gauge the sensitivity of estimates effects of smoking on cost, controlling and not controlling for these other activities.

Another issue is whether the comparison group is between current smokers and those who have never smoked or between smokers and some category of former smokers. The appropriate choice depends on the question being asked. Comparing current and former smokers would be relevant for assessing benefits of smoking cessation interventions, but not for assessing benefits of preventing initiation for which those who have never smoked are the appropriate reference group.

\section{Previous Studies}

\section{Life-Cycle Approach}

Empirical implementation of the life-cycle approach is illustrated by a recent article by Barendregt et al. (1997), which applied the approach for the Netherlands. For their calculations, the authors used data on age- and gender-specific incidence and prevalence of five major diseases: heart disease, stroke, lung cancer, a heterogeneous group of other cancers, and chronic obstructive pulmonary disease (COPD). They obtained data on the per capita cost of each of these diseases. The residual category was all other diseases, which accounted for the difference between total costs of health care and the cost of the five diseases, expressed per capita population. Unlike the five diseases, frequency of the residual disease category varied by age and gender, but not by smoking status. The authors used three life tables: one for a mixed population of smokers and nonsmokers, one for a population of smokers, and one for a population of nonsmokers. Expected cost was discounted at alternative rates, ranging from 0 to 10 percent.

Per capita costs rose sharply with age, increasing tenfold between the base age 40 to 44 years of age to 85 to 89 years of age. At age 65 to 74 , per capita cost was 40 percent higher for male smokers and 25 percent higher for female smokers. However, considering the number of smokers alive by age, the total cost of care for various age cohorts of male smokers peaked to about age 65 to 69 . For male nonsmokers, the total cost of care peaked about age 75 to 79 . Far more (over three times) was spent on behalf of male nonsmokers aged 85 to 89 than on male 
smokers of the same age. The authors simulated changes in total health costs for the male population after smoking cessation. Regardless of the discount rate used, smoking cessation caused an initial drop in spending. As the population aged, however, spending increased. Thus, for example, using the most plausible discount rate of 3 percent, thirty-one years after cessation, encouraging people to stop smoking actually increased spending. Using a lower discount rate decreased the breakeven year; with a higher rate, the breakeven year was greater than thirty-one years.

Other longitudinal studies have yielded different results. Several studies have found smoking to result in higher medical cost, but the amount of the increase depended on the discount rate used and other underlying assumptions (Oster et al. 1984; Leu and Schaub 1985; Manning et al. 1991; Hodgson 1992). Leu and Schaub (1985), a study of Swiss males, found higher expenditures for nonsmokers than smokers, a result consistent with the study from the Netherlands. According to Miller et al. (1997), however, "There is some evidence that Leu and Schaub underestimated the level of excess medical care associated with smokers" (p. 5).

The prevalence approach has been widely used in studies by experts for plaintiffs in tobacco litigation (see, for example, Harris 1997; Max 1997). The general methodology is to derive smoking-attributable fractions for particular health services, such as for hospital care, and apply these fractions to data on expenditures. The smoking-attributable fractions consistently imply excess spending on behalf of smokers (see, for example, Miller et al. 1997, 1999) and therefore are favorable to plaintiffs in such litigation. Thus, smoking-related cost is always positive as well. These studies have been criticized by experts for the defense on grounds that they underadjust for behaviors other than smoking and fail to account for premature death due to smoking (see, for example, Rubin 1997). Quoting Viscusi (1999), "There are no damages to the state in terms of higher Medicaid costs once smokers are dead" (p. 590).

Several studies have extended analysis of the consequences of smoking to include a larger number of types of costs-sick leave, group life insurance, retirement pensions, and fire (see, in particular, Atkinson and Townsend 1977; Manning et al. 1989, 1991; Viscusi 1995, 1999). The largest addition to cost from smoking is medical care cost, excluding cost of nursing home care. The largest savings from smoking are in terms of reduced pension cost and in the cost of nursing home care. 


\section{Methods and Empirical Specification}

The HRS was conducted in two-year intervals. We defined explanatory variables for the preceding wave. Thus, utilization of health care services between the waves was made to depend on levels of variables in the previous wave. For this reason, our panel used Waves 2 to 4, with Wave 1 used exclusively for information on explanatory variables.

Our measures of personal health services were the number of nights in the hospital, number of visits to physicians, and whether or not the person was admitted to a nursing home during the two years before the survey. In this age cohort, very few persons are admitted to nursing homes.

The key explanatory variables relate to smoking behavior. We defined binary variables for current smokers, former smokers who quit smoking from five to ten, eleven to nineteen, and twenty or more years before the preceding interview with those who have never smoked, the omitted reference group. We combined persons who quit less than five years before the preceding interview with current smokers because (1) such persons are much more likely to relapse and (2) short-term quitting is often motivated by an adverse health event. As stressed by Moore and Hughes (2001) in Chapter 2 of this volume, recent quitting may reflect occurrence of recent health shocks. In fact, in preliminary analysis, we found that persons who quit smoking in the past five years were higher utilizers of medical care services on average than were current smokers.

Other explanatory variables were either time-varying or time-invariant. Time-varying explanatory variables were household income, marital status, self-reported health, body mass index (for height in relationship to weight), and insurance status. The insurance categories were Medicare disabled, Medicare elderly, Medicaid, other government, private individual, and private group coverage. Some sample persons had more than one type of coverage. We distinguished between Medicare disabled and elderly based on the person's age. If under age 65 at the interview, the Medicare enrollee was classified in the former group. To develop mutually exclusive health insurance categories, we developed a hierarchy of types. For example, if a person had both Medicare and Medicaid, we considered the person to be covered by Medicare. A person was considered to be uninsured only if she or he had no other source of coverage. 
Time-invariant variables were alcohol consumption, including self-identified problem drinkers; a risk tolerance measure (see Barsky et al. 1997); gender; education; and race. We also included a variable for year and age, which varied by wave.

To assess the effect of smoking behavior on numbers of hospital nights and physician visits, we estimated a random effects negative binomial model (Hausman et al. 1984). A random effects negative binomial has several appealing features. First, it deals explicitly with count data. Second, it allows for inclusion of covariates. Third, it accounts for the large proportion of zeros in our utilization measures and the skewed distribution of positive values. Fourth, it allows for overdispersion (variance greater than the mean), unlike the Poisson model. Fifth, it takes advantage of the panel feature of our data by accounting for persistent individual random effects. To gauge effects of smoking on nursing home use, we estimated a random effect logit model.

Using data on mortality between Waves 1 and 2, we estimated logit models for males and females to analyze determinants of survival, particularly, the effects of smoking. We used the same explanatory variables used to assess determinants of utilization. All such variables were measured at Wave 1. With parameter estimates from these models, we constructed life tables for current smokers, former smokers, nonsmoking smokers, nonsmoking former smokers, and those who have never smoked. A nonsmoking smoker is a person with the characteristics of smokers except that the person does not smoke.

We created thirteen categories for thirteen representative individuals: current smoker; former smoker who quit (1) two years ago, (2) seven years ago, (3) thirteen years ago, (4) eighteen years ago, and (5) twenty-three years ago; those who have never smoked; nonsmoking smoker; and five nonsmoking former smokers. The total number of hospital nights and physician visits for persons between the ages of 51 and 67 were estimated as follows. First, we created life tables for fifty-one-year-old male and female representative individuals based on estimates from the hazard models. Second, we created eight two-year periods. Third, for each period, we simulated survival for each period. Fourth, using coefficients from the negative binomial model, we simulated the number of hospital nights and physician visits that a representative individual had in that period. If, according to the simulation, the individual survived the period, we used this simulated amount for health services utilization. But if the individual died during the period, we assumed that the person used 3.5 times as much care. Fifth, if the in- 
dividual was predicted to have died, this utilization level was final. If the individual was predicted to have survived, we updated the characteristics of the representative individuals by (1) updating the period (to account for trends in medical utilization), (2) updating the number of years since quitting for former smokers, and (3) forcing 10 percent of the current smokers to become former smokers. We did not allow for relapsing, but relapsing was uncommon in our sample, especially after smokers had quit for several years. Sixth, we repeated the fourth and fifth steps until the individual was predicted to die or the eighth period was reached.

We used alternative discount rates of 0 and 3 percent. We simulated utilization for 1,000 representative smokers, smokers who had never smoked, and those who had never smoked 100 times. We computed means from each sample of 1,000 representative individuals and report the means and standard deviations based on the 100 samples.

Finally, to study effects of smoking on insurance status, we estimated a multinomial logit model. Mutually exclusive categories for the dependent variable were being uninsured, covered by Medicare, covered by Medicaid, having other public coverage, or private individual coverage. The omitted reference group was private group coverage. We used the same explanatory variables as in the previous multivariate analyses (except, of course, insurance status). All variables were measured for Wave 1.

Simulated changes in utilization for all individuals were obtained in the following way. First, we calculated the weighted average of utilization of smokers; former smokers who quit two, seven, thirteen, eighteen, and twenty-three years ago, and those who had never smoked. Second, we calculated the weighted average of utilization for nonsmoking smokers, nonsmoking former smokers who quit two, seven, thirteen, eighteen, and twenty-three years ago, and those who had never smoked. Third, we calculated the percentage difference between the two amounts. To calculate simulated changes in utilization for each payer, we adjusted the weights based on the likelihood of each individual using a particular payer.

The likelihood of each individual using a particular payer was calculated from the predicted probabilities of the multinomial choice model described above. For the counterfactual, nonsmoking smokers, we calculated these probabilities, switching the smoking variable off (that is, setting the binary equal to zero), but holding all other characteristics of that individual constant. 
To translate utilization differences in cost to each payer, we used data on cost per hospital day (U.S. Department of Commerce 1999, Table 203), adjusted for price-cost margins paid by each payer (U.S. Prospective Payment Assessment Commission 1995, p. 21) and prices per physician encounter (U.S. Department of Commerce 1999, Tables 184 and 198), and also adjusted for payer payment differentials (U.S. Physician Payment Review Commission 1995, pp. 77-84).

\section{Results}

\section{Longitudinal Smoking Patterns}

Once a person quit smoking, restarting was relatively unusual (table 1.1). Among persons who reported smoking at Wave 1 , the propensity to smoke at subsequent waves fell monotonically. At Wave 2, 83 percent continued to smoke, but at Wave 3, only 79 percent of Wave 1 current smokers did. By Wave 4, only 70 percent of these individuals said they were current smokers. Among persons who said that they quit between one to four years before the Wave 1 interview, nearly 6 percent had restarted by Wave 2; the proportion of these persons who restarted by Waves 3 and 4 were even higher. Thus, for a nontrivial subset of such individuals, not smoking at Wave 1 was only temporary. For this reason, in our empirical analysis, we combined current smokers and those who had quit within five years of the interview into a single category for our analysis of mortality, utilization of personal health care services, and choice of health insurance type.

Between 2 and 3 percent of persons who had quit for five to nine years at the baseline survey resumed smoking subsequently. For former smokers who had quit ten to nineteen years earlier, had quit twenty years earlier, or had never smoked, restarting occurred in 1 percent or less of cases. Overall the percentage of smokers declined from 28 percent in Wave 1 to slightly less than 20 percent by Wave 4 (figure 1.1). In part, the decline reflected higher mortality rates among smokers, but most of the change is attributable to high smoking cessation rates among persons in this age cohort.

\section{Health Insurance}

Sources of payment for personal health insurance shifted dramatically over the six-year period, probably more so than is typical for other age 
Table 1.1

Current smokers at Waves 2 to 4 conditional on smoking status at Wave 1 (\%)

\begin{tabular}{lrrr}
\hline Smoking variable & Wave 2 & Wave 3 & Wave 4 \\
\hline Current & 83.25 & 78.58 & 69.82 \\
Former 1 to 4 years & 5.78 & 7.41 & 7.61 \\
Former 5 to 9 years & 2.26 & 2.69 & 2.24 \\
Former 10 to 19 years & 1.36 & 1.21 & 1.32 \\
Former more than 20 & 0.79 & 1.04 & 0.90 \\
Never & 0.59 & 0.37 & 0.36 \\
& & & 7198.00 \\
\hline $\mathrm{N}$ & 8535.00 & 7803.00 &
\end{tabular}

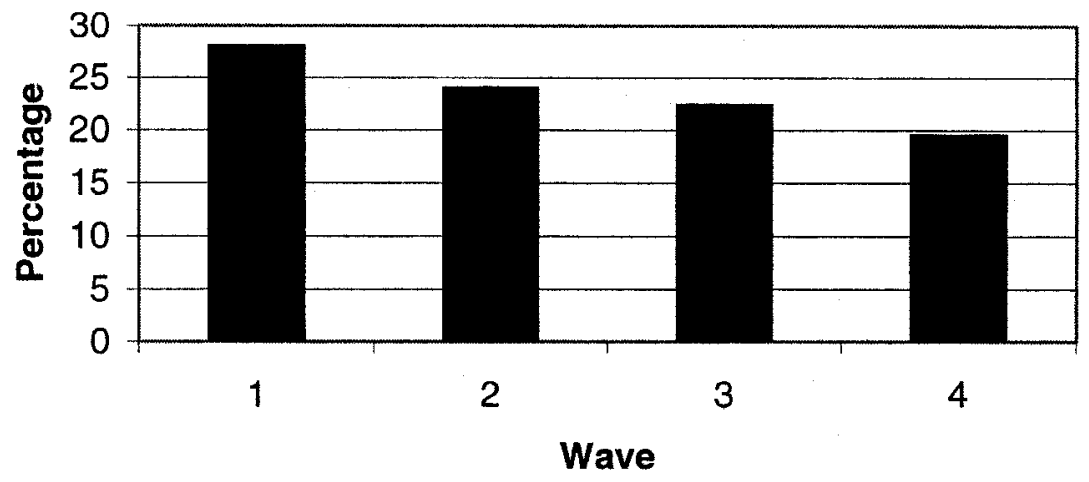

Figure 1.1

Current smokers by wave

cohorts (table 1.2). For the sample as a whole, the single largest primary source of health insurance was private group insurance. Between Waves 1 and 4, however, the percentage of persons with such coverage dropped from 65 to 48 percent. By Wave 4, Medicare was the second most important payer, consisting of about three-quarters of persons eligible for Medicare based on age, with the remainder eligible based on disability. Only between 3 to 4 percent of persons in this age group had Medicaid as the primary source of health insurance. Less than 10 percent had individual private health insurance coverage. At Wave 1, nearly 17 percent of persons had no health insurance; by Wave 4, only 10 percent of persons fell in this category. The decrease in uninsured individuals was primarily caused by persons becoming age-eligible for Medicare. 
Table 1.2

Health insurer by Wave (\%)

\begin{tabular}{lrrrr}
\hline Insurer & Wave 1 & Wave 2 & Wave 3 & Wave 4 \\
\hline Uninsured & 16.57 & 13.11 & 11.83 & 9.83 \\
Medicare disabled & 3.93 & 5.76 & 7.85 & 7.54 \\
Medicare elderly & 0.00 & 0.00 & 4.14 & 18.43 \\
Medicaid & 3.37 & 3.68 & 3.76 & 3.11 \\
Other government & 5.61 & 5.33 & 4.85 & 4.30 \\
Group insurance & 65.41 & 65.87 & 57.96 & 48.17 \\
Individual insurance & 5.12 & 6.24 & 9.60 & 8.62 \\
& & & & 7112.00 \\
$\mathrm{~N}$ & 9399.00 & 8535.00 & 7581.00 &
\end{tabular}

At Wave 1, 28 percent of persons smoked or had quit within five years of the interview (table 1.3). Such persons were overrepresented among the uninsured, accounting for 36 percent of the uninsured. They also accounted for more than their share of Medicare disabled, Medicaid, and other public programs. They were underrepresented among the privately insured, both for group and individual coverage. Although the percentages differed at Wave 4, the conclusion that smokers are disproportionately covered by public programs and are uninsured did not change. However, smokers were underrepresented among the elderly on Medicare (persons between 65 and 67).

Those who had never smoked comprised 37 percent of the sample at Wave 1 and 38 percent at Wave 4 . Relative to the total sample, these persons were more likely to have individual health insurance coverage and less likely to have coverage from government programs other than Medicare or Medicaid.

Adjusting for the influence of other factors using multinomial logit analysis of data from Wave 1 did not alter these findings (table 1.4). Current smokers were more likely to have been uninsured or have various forms of government insurance. They were least likely to have private individual insurance, although the difference between this category and private group coverage, the omitted reference group, was not statistically significant at conventional levels. Gauged in terms of differences in probabilities predicted from this model, current smokers were 0.0009 more likely to be uninsured; 0.010, 0.0003, and 0.030 more likely to be on Medicare, Medicaid, or have other government coverage, respectively; and 0.006 less likely to have private individual 


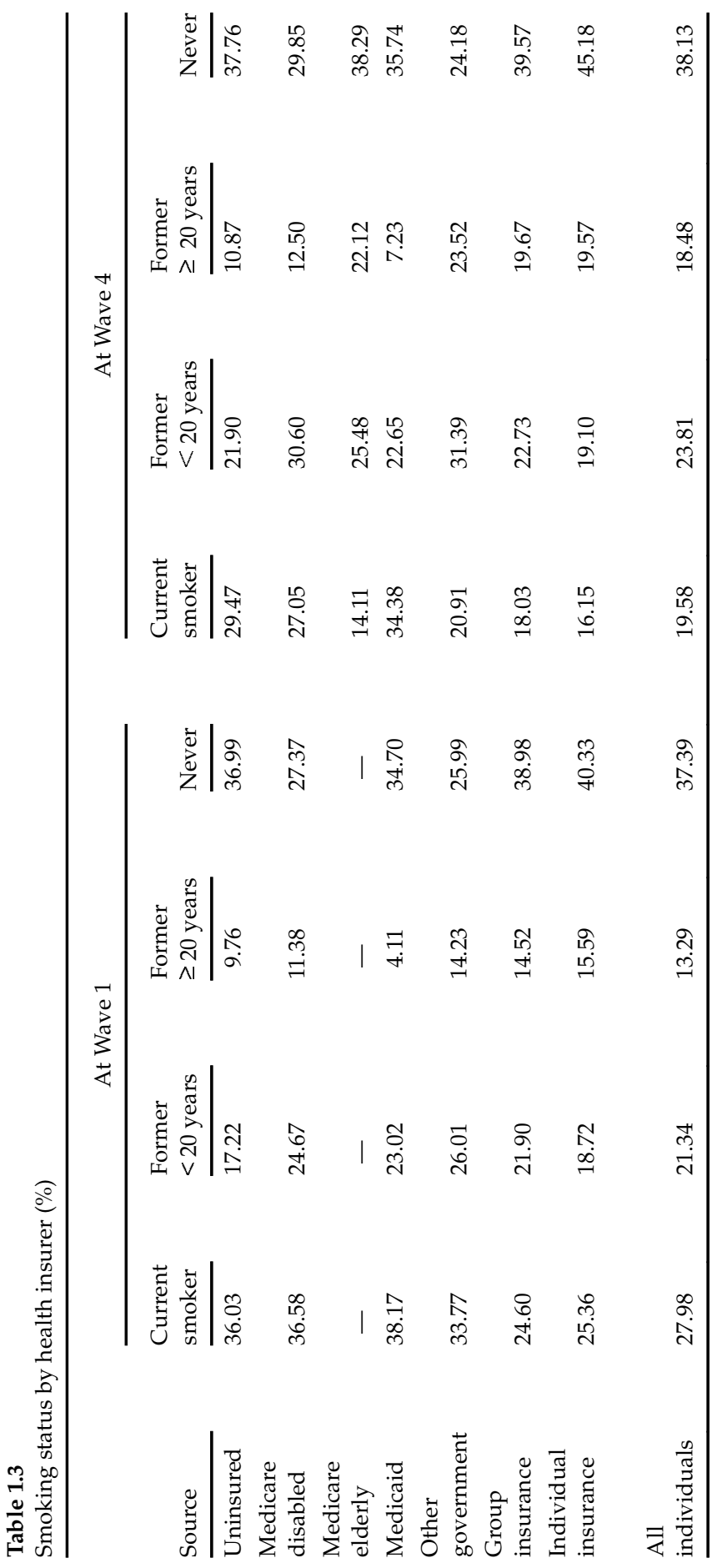


Table 1.4

Effects of smoking on health insurance coverage at Wave 1: results from multinomial logit analysis ${ }^{\mathrm{d}}$

\begin{tabular}{|c|c|c|c|c|c|}
\hline Smoking variable & Uninsured & Medicare & Medicaid & $\begin{array}{l}\text { Other } \\
\text { government }\end{array}$ & Individual \\
\hline $\begin{array}{l}\text { Current }+ \text { former, } \\
1 \text { to } 4 \text { years }\end{array}$ & $\begin{array}{l}0.083 \\
(1.07) \\
{[0.0009]}\end{array}$ & $\begin{array}{l}0.372^{\mathrm{b}} \\
(2.50) \\
{[0.010]}\end{array}$ & $\begin{array}{l}0.230 \\
(1.42) \\
{[0.003]}\end{array}$ & $\begin{array}{l}0.624^{\mathrm{a}} \\
(5.01) \\
{[0.030]}\end{array}$ & $\begin{array}{l}-0.05 \\
(-0.48) \\
{[-0.006]}\end{array}$ \\
\hline $\begin{array}{l}\text { Former, } 5 \text { to } \\
9 \text { years }\end{array}$ & $\begin{array}{c}-0.124 \\
(-0.848) \\
{[-0.021]}\end{array}$ & $\begin{array}{l}0.451^{\mathrm{c}} \\
(1.87) \\
{[0.016]}\end{array}$ & $\begin{array}{l}0.324 \\
(1.16) \\
{[0.009]}\end{array}$ & $\begin{array}{l}0.372^{\mathrm{c}} \\
(1.75) \\
{[0.017]}\end{array}$ & $\begin{array}{l}-0.42^{c} \\
(-1.64) \\
{[-0.018]}\end{array}$ \\
\hline $\begin{array}{l}\text { Former, } 10 \text { to } \\
19 \text { years }\end{array}$ & $\begin{array}{l}-0.159 \\
(-1.26) \\
{[-0.026]}\end{array}$ & $\begin{array}{l}0.354^{\mathrm{c}} \\
(1.64) \\
{[0.012]}\end{array}$ & $\begin{array}{c}0.159 \\
(0.614) \\
{[0.004]}\end{array}$ & $\begin{array}{l}0.523^{\mathrm{a}} \\
(3.13) \\
{[0.026]}\end{array}$ & $\begin{array}{l}-0.062 \\
(-0.33) \\
{[-0.004]}\end{array}$ \\
\hline $\begin{array}{l}\text { Former, more } \\
\text { than } 20\end{array}$ & $\begin{array}{l}-1.550 \\
(-1.36) \\
{[-0.020]}\end{array}$ & $\begin{array}{l}0.304 \\
(1.50) \\
{[0.012]}\end{array}$ & $\begin{array}{c}-0.552^{c} \\
(1.68) \\
{[-0.011]}\end{array}$ & $\begin{array}{l}0.242 \\
(1.52) \\
{[0.011]}\end{array}$ & $\begin{array}{c}0.101 \\
(0.65) \\
{[-0.005]}\end{array}$ \\
\hline
\end{tabular}

${ }^{a}$ Significant at the $1 \%$ level (two-tail test).

${ }^{\mathrm{b}}$ Significant at the $5 \%$ level (two-tail test).

c Significant at the $10 \%$ level (two-tail test).

$\mathrm{d}$ t-ratio in parentheses; marginal effects in brackets.

coverage than were those who had never smoked. Although these differences in probability appear to be small, they are sometimes large relative to the proportion of persons in the age cohort with the type of coverage, such as for other government insurance coverage that underlies the large effect of smoking for this payer category (to be discussed below).

The difference in the probability of having private group coverage (not shown in table 1.4) was 0.049, implying that current smokers were less likely to have group insurance than was the case for those who had never smoked. Although those who had never smoked were less likely to have been uninsured than were current smokers, they were more likely to be uninsured than were persons who had quit, especially persons who had quit twenty or more years before the Wave 1 interview.

Many other parameter estimates, not shown in the table, were plausible. For example, risk averse persons were more likely to have some form of health insurance, a result previously reported by Barsky et al. (1997). Older persons were more likely to be uninsured or have public insurance, including Medicare. Since the analysis was based on Wave 1, none of the respondents had become age eligible for Medicare. 
Older persons within the age cohort were least likely to have private group coverage.

\section{Utilization of Personal Health Care Services}

We measured the impact of smoking on utilization of health services, controlling and not controlling for self-reported health. In general, the results were quite similar, and we report only results without these controls because not controlling for self-reported health is more conceptually appropriate. (To the extent that smoking affects self-reported health, one should not control for this factor.)

For hospital care, effects of smoking status on use were positive for current and for all of the former smoking categories (table 1.5). Current smokers had the highest rates of use, with a relative risk of 1.29 , followed by persons who had quit for five to nine years at the prior wave, with a relative risk of 1.21; the influence of smoking was less for those who had quit ten to nineteen years before the prior wave, with a relative risk of 1.14. The relative risk for persons who had quit twenty or more years previously was essentially the same as for those who had never smoked, the omitted reference group.

Other relationships, not presented, were plausible. For example, use by the uninsured was the lowest, other factors being equal, and use by Medicare beneficiaries was the highest, holding age and other factors constant. In general, privately insured individuals had lower rates of hospital use than did those with public insurance.

For number of visits, the effect of smoking status on use was less clear. Current smokers had essentially the same rates of use as those who had never smoked. By contrast, those who quit from five to nine years and ten to nineteen years before the interview saw physicians more often than did those who had never smoked. The relative risk for both groups of quitters was 1.13. When we controlled for self-reported health (not shown), the differential in visit rates between current smokers and those who had never smoked was even larger, and this difference was statistically significant at better than the 5 percent level. We prefer the specification without self-reported health because health is itself affected by smoking. We controlled for many other factors, including type of health insurance, education, income, and degree of risk aversion. Results for most of the other explanatory variables were plausible.

In this age cohort, being in a nursing home is a rare event. Although the number of respondents spending time in a nursing home increased 
Table 1.5

Effects of smoking on utilization of personal health services: results from random effects negative binomial and logit analysis

\begin{tabular}{|c|c|c|c|c|c|c|}
\hline \multirow[b]{2}{*}{ Smoking variable } & \multicolumn{2}{|c|}{ Hospital nights } & \multicolumn{2}{|c|}{ Physician visits } & \multicolumn{2}{|c|}{ Nursing home } \\
\hline & Relative risk & $\mathrm{t}$ & Relative risk & $t$ & Relative risk & $\mathrm{t}$ \\
\hline $\begin{array}{l}\text { Current }+ \text { former } 1 \text { to } \\
4 \text { years }\end{array}$ & $1.29^{\mathrm{a}}$ & 6.44 & 0.98 & -0.806 & $1.87^{\mathrm{c}}$ & 1.63 \\
\hline Former, 5 to 9 years & $1.21^{\mathrm{a}}$ & 2.94 & $1.13^{\mathrm{a}}$ & 4.23 & 1.40 & 0.52 \\
\hline Former, 10 to 19 years & $1.14^{\mathrm{b}}$ & 2.45 & $1.13^{\mathrm{a}}$ & 4.38 & 2.13 & 1.53 \\
\hline Former, more than 20 & 0.92 & -1.35 & 1.02 & 1.62 & 1.78 & 1.18 \\
\hline
\end{tabular}

a Significant at the $1 \%$ level (two-tail test).

${ }^{b}$ Significant at the $5 \%$ level (two-tail test).

${ }^{\mathrm{c}}$ Significant at the $10 \%$ level (two-tail test).

for each of the waves, the number was very low: Wave 1-11, Wave 2-14, Wave 3-21, Wave 4-25. Among the users, the overwhelming majority of persons stayed in the nursing home for a month or less, suggesting that most of this utilization was for post-hospital stays. Thus, in our logit analysis of nursing home use, we distinguished only between users and nonusers. Even with this very small sample of users, the coefficient on current users was positive and statistically significant at the 10.3 percent level. Coefficients for the former smokers were also positive, although statistically significant at lower levels than the 10.3 level. Including self-reported health only had a slight influence on the estimated parameters. For all of the categories of current and former smokers, the odds ratios well exceeded 1.0, suggesting that, with more statistical power, statistically significant relationships may have been obtained.

Not surprisingly (results not shown), given the distribution of length of stay, having Medicare increased the number of nights in a nursing home; by contrast, being on Medicaid had no effect.

\section{Mortality}

Current smokers have a much higher rate of death than those who had never smoked (table 1.6). For males, the hazard ratio was 3.59 and for females, 1.89; both parameter estimates were statistically significant. For males, hazard ratios for former smokers who quit five to nine years before the interview were around 3.48; for those who quit ten to nineteen years earlier, 2.06; and for persons who had quit more than twenty 
Table 1.6

Effects of smoking on mortality

\begin{tabular}{|c|c|c|c|c|}
\hline \multirow[b]{2}{*}{ Smoking variable } & \multicolumn{2}{|c|}{ Male } & \multicolumn{2}{|c|}{ Female } \\
\hline & Relative risk & $\mathrm{t}$ & Relative risk & $\mathrm{t}$ \\
\hline Current + former 1 to 4 years & $3.59^{\mathrm{a}}$ & 3.34 & $1.89^{\mathrm{c}}$ & 1.87 \\
\hline Former, 5 to 9 years & $3.48^{\mathrm{b}}$ & 2.51 & 1.09 & 0.12 \\
\hline Former, 10 to 19 years & 2.06 & 1.45 & 0.61 & -0.64 \\
\hline Former, more than 20 & 1.59 & 0.77 & 0.87 & -0.20 \\
\hline
\end{tabular}

${ }^{a}$ Significant at the $1 \%$ level (two-tail test).

b Significant at the $5 \%$ level (two-tail test).

c Significant at the $10 \%$ level (two-tail test).

years earlier, the hazard ratio was 1.59 , but not statistically significant at conventional levels. For females, hazard ratios were consistently lower than for males and, except for current smokers, not statistically significant. Effects of smoking were quite robust to changes in equation specification.

Other results (not shown) were generally plausible. For males, the following variables had statistically significant and positive impacts on deaths-age, being on Medicare, being on Medicaid, and one of the measures of heavy drinking at the baseline interview. Being married reduced the probability of dying. Risk preferences had no impact on mortality. Not accounting for risk preferences has been a criticism of studies used by plaintiffs in tort litigation (see, for example, Hersch and Viscusi, 1990, for specific evidence on the link between smoking and other risky behaviors). For females, only age and being on Medicaid (other than being a current smoker) had positive and statistically significant effects on mortality at the 5 percent level or better.

Based on these coefficients, we created life tables for all our smoking categories. For the overall sample, our life tables produced very similar hazard rates to those constructed for the total population in 1997 by the U.S. Centers for Disease Control and Prevention (1999). For example, for males, our life table yielded a 1.28 hazard rate for two years at 51 and 4.39 at 65 . The CDC life table yielded rates of 1.27 and 4.38, respectively.

\section{Simulated Utilization by Smoking Status}

Simulated utilization by nonsmoking current smokers was far more similar to those who had never smoked than to current smokers, 
Table 1.7

Simulated utilization for sixteen years for person age 51 by smoking status

\begin{tabular}{|c|c|c|c|c|}
\hline \multirow[b]{2}{*}{ Smoking status } & \multicolumn{2}{|c|}{ Male } & \multicolumn{2}{|c|}{ Female } \\
\hline & Hospital nights & Physician visits & Hospital nights & Physician visits \\
\hline Current smokers & $\begin{array}{l}11.82 \\
(0.56)\end{array}$ & $\begin{array}{l}56.69 \\
(1.05)\end{array}$ & $\begin{array}{l}10.59 \\
(0.52)\end{array}$ & $\begin{array}{l}72.33 \\
(1.10)\end{array}$ \\
\hline \multicolumn{5}{|l|}{ Former smoker } \\
\hline Quit 2 years ago & $\begin{array}{l}10.73 \\
(0.49)\end{array}$ & $\begin{array}{l}60.91 \\
(1.00)\end{array}$ & $\begin{array}{c}9.92 \\
(0.44)\end{array}$ & $\begin{array}{l}78.42 \\
(0.99)\end{array}$ \\
\hline Quit 7 years ago & $\begin{array}{l}10.03 \\
(0.44)\end{array}$ & $\begin{array}{l}62.39 \\
(1.05)\end{array}$ & $\begin{array}{c}9.14 \\
(0.39)\end{array}$ & $\begin{array}{l}80.46 \\
(1.19)\end{array}$ \\
\hline Quit 13 years ago & $\begin{array}{c}9.17 \\
(0.40)\end{array}$ & $\begin{array}{l}61.41 \\
(0.95)\end{array}$ & $\begin{array}{c}8.20 \\
(0.38)\end{array}$ & $\begin{array}{l}78.24 \\
(1.09)\end{array}$ \\
\hline Quit 18 years ago & $\begin{array}{c}8.41 \\
(0.42)\end{array}$ & $\begin{array}{l}59.99 \\
(0.88)\end{array}$ & $\begin{array}{c}7.38 \\
(0.40)\end{array}$ & $\begin{array}{l}76.31 \\
(1.01)\end{array}$ \\
\hline Quit 23 years ago & $\begin{array}{c}8.16 \\
(0.42)\end{array}$ & $\begin{array}{l}59.81 \\
(0.76)\end{array}$ & $\begin{array}{c}7.16 \\
(0.35)\end{array}$ & $\begin{array}{l}75.69 \\
(0.97)\end{array}$ \\
\hline $\begin{array}{l}\text { Those who have } \\
\text { never smoked }\end{array}$ & $\begin{array}{l}8.65 \\
(0.38)\end{array}$ & $\begin{array}{l}57.29 \\
(0.81)\end{array}$ & $\begin{array}{l}7.93 \\
(0.37)\end{array}$ & $\begin{array}{l}71.62 \\
(1.00)\end{array}$ \\
\hline \multicolumn{5}{|l|}{ Nonsmoking } \\
\hline Current & $\begin{array}{c}9.52 \\
(0.43)\end{array}$ & $\begin{array}{l}56.83 \\
(0.75)\end{array}$ & $\begin{array}{c}8.53 \\
(0.48)\end{array}$ & $\begin{array}{l}71.34 \\
(0.93)\end{array}$ \\
\hline Quit 2 years ago & $\begin{array}{c}9.18 \\
(0.42)\end{array}$ & $\begin{array}{l}56.98 \\
(0.97)\end{array}$ & $\begin{array}{c}8.46 \\
(0.41)\end{array}$ & $\begin{array}{l}72.30 \\
(0.97)\end{array}$ \\
\hline Quit 7 years ago & $\begin{array}{c}9.03 \\
(0.44)\end{array}$ & $\begin{array}{l}57.24 \\
(0.97)\end{array}$ & $\begin{array}{c}8.29 \\
(0.40)\end{array}$ & $\begin{array}{l}72.44 \\
(1.14)\end{array}$ \\
\hline Quit 13 years ago & $\begin{array}{c}8.86 \\
(0.40)\end{array}$ & $\begin{array}{l}57.25 \\
(0.85)\end{array}$ & $\begin{array}{r}7.96 \\
(0.42)\end{array}$ & $\begin{array}{l}71.68 \\
(0.93)\end{array}$ \\
\hline Quit 18 years ago & $\begin{array}{c}8.78 \\
(0.42)\end{array}$ & $\begin{array}{l}57.27 \\
(0.87)\end{array}$ & $\begin{array}{l}7.82 \\
(0.42)\end{array}$ & $\begin{array}{l}71.06 \\
(1.02)\end{array}$ \\
\hline Quit 23 years ago & $\begin{array}{c}8.75 \\
(0.39)\end{array}$ & $\begin{array}{l}57.31 \\
(0.78)\end{array}$ & $\begin{array}{c}7.69 \\
(0.37)\end{array}$ & $\begin{array}{l}71.03 \\
(1.09)\end{array}$ \\
\hline
\end{tabular}

reflecting that the other characteristics had only a minor impact on utilization relative to the effect of being a smoker (table 1.7). The same pattern resulted for former smokers. The effect of being a former smoker was far greater than the effect on utilization of the characteristics of former smokers versus those of people who had never smoked. By characteristics, we include characteristics affecting both utilization and mortality.

We show utilization for the sixteen-year period discounted at 3 percent. We also simulated utilization using a zero discount rate (not shown). Discounting has the effect of decreasing the utilization 
differences. With discounting at 3 percent, male current smokers were predicted to have 2.3 additional nights in the hospital over the sixteen-year period relative to nonsmoking current smokers, a 24.1 percent increase, and 3.17 nights relative to those who had never smoked, a 36.6 percent increase. For females, the corresponding differentials at a 3 percent discount were 2.06 nights, or 24.1 percent, and 2.66, or 33.5 percent, respectively.

Being a former smoker decreased the number of hospital nights relative to current smokers. As the period of quitting increased, the difference between hospitalization of former smokers and those who had never smoked decreased. For male former smokers who quit eighteen and twenty-three years before the interview, use was even lower than for those who had never smoked. For female former smoking, the comparison between former smokers and those who had never smoked was relatively more favorable for former smokers than for males. For some categories, the nonsmoking former smoker adjustment boosts hospital utilization.

The pattern for physician visits is more complex. Utilization over the sixteen-year period was simulated to be lower for male current smokers than for those who had never smoked: 56.69 versus 57.29 , or -1 percent lower. Physician visits by male nonsmoking current smokers was 56.83; visit rates among current smokers are -0.2 percent lower than this group. Female use of physician services was uniformly higher than for males. For females, the differential between current smokers and those who had never smoked was 0.7 visits, or 0.9 percent. Between current and nonsmoking current smokers, the difference was greater: one visit, or 1.3 percent. This finding implies that smokers' characteristics per se decrease demand for physician services. For females, former smokers uniformly had more physician visits compared to those who had never smoked.

\section{Simulated Utilization by Payer}

Overall, for males, smoking and having smoked in the past increased hospital utilization and the number of physician visits over the sixteen-year period, starting at age 51, by 8.72 and 2.29 percent, respectively (table 1.8). For females, the corresponding increases were 7.49 and 2.42 percent, respectively. These percentage estimates reflect mortality, utilization, and cessation propensities. These differentials compare smoking patterns as of the HRS interviews with a world in which no one smoked. 
Table 1.8

Percentage simulated changes in utilization by payer

\begin{tabular}{|c|c|c|c|c|}
\hline \multirow[b]{2}{*}{ Payer } & \multicolumn{2}{|c|}{ Male } & \multicolumn{2}{|c|}{ Female } \\
\hline & $\begin{array}{l}\text { Hospital } \\
\text { nights }\end{array}$ & $\begin{array}{l}\text { Physician } \\
\text { visits }\end{array}$ & $\begin{array}{l}\text { Hospital } \\
\text { nights }\end{array}$ & $\begin{array}{l}\text { Physician } \\
\text { visits }\end{array}$ \\
\hline Uninsured & 1.94 & -6.30 & 8.33 & 1.54 \\
\hline Medicare & 27.18 & 12.73 & 32.76 & 24.29 \\
\hline Medicaid & 22.16 & 8.83 & 17.03 & 8.29 \\
\hline Other government & 55.39 & 43.38 & 45.50 & 35.82 \\
\hline Group insurance & 4.54 & -0.62 & 4.94 & 0.79 \\
\hline Individual insurance & 0.25 & -4.63 & 1.68 & -2.49 \\
\hline All individuals & 8.72 & 2.29 & 7.49 & 2.42 \\
\hline
\end{tabular}

The differences by payer are striking. The largest differentials were for the other government group, which includes Champus and the Veterans Administration. For males, smoking caused a 55.39 percent increase in hospital use and a 43.38 percent increase in physician visit rates. The hospital differential was about half this for Medicare while, for physicians' services, the differential for Medicare is 12.73 percent. For males on Medicaid, the differentials were somewhat less, but still sizable: 22.16 percent for hospital use and 8.83 percent for physician visits. By comparison, private payers incurred little loss from smoking or even benefit. This finding was particularly true of private individual insurance. For females, patterns were the same qualitatively but with differences in details.

Simulated changes in utilization were based on predicted payer status from the multinomial logit analysis using data from Wave 1 (table 1.8). There were two assumptions underlying the calculations. First, we assumed that persons stayed with the payer they had initially. In fact, many switched to Medicare at age 65. Thus, the burden on Medicare was somewhat understated and the burden on other payers, such as Medicaid, slightly overstated but nevertheless substantial. The second assumption was that our counterfactual nonsmoking smokers' choice of insurance could be accurately predicted from the multinomial logit, holding all other characteristics constant, except for the smoking variables. The large difference in incidence by payer was due to the fact that smokers were more likely to have health insurance from public sources. 
Table 1.9

Cost of smoking by payer (\%)

\begin{tabular}{lcc}
\hline Payer & Male & Female \\
\cline { 3 - 3 } Uninsured & -0.77 & 5.50 \\
Medicare & 22.21 & 29.18 \\
Medicaid & 18.08 & 13.69 \\
Other government & 51.23 & 41.39 \\
Group insurance & 2.73 & 3.16 \\
Individual insurance & -1.45 & -0.10 \\
All individuals & & \\
\hline
\end{tabular}

\section{Cost of Smoking by Payer}

For males, smoking increased by 6.4 percent in the aggregate (table 1.9). The corresponding estimate for females was 5.2 percent. As with utilization, the large impact was for other government, followed by Medicare and Medicaid. Effects of the privately insured and the uninsured were negligible. We obtained no consistent relationship between the estimated impacts for males as contrasted with females. For other government, the males' effect was higher; women were half as likely to be covered by other government insurance as were men. Thus, the impact for this group was fairly imprecise. For Medicare, the cost impact was higher for women than men, and the reverse was true for Medicaid.

\section{Discussion and Conclusions}

For this age group, smoking increased medical utilization and dollar outlays by 5 to 8 percent on average, with substantial variation in incidence by payer. Public payers bore a disproportionate burden. This increase was net of various offsets for mortality and smoking cessation. Accounting for the effects of smoking on payer choice is critical to accurate accounting of smoking-attributable costs.

Severe limitations of this study should be noted. First, we did not study the effects of smoking cessation on medical spending. Rather, our objective was to measure the health expenditure burden that smoking imposes. Although we "switched off" smoking to compute the burden of smoking, our estimates do not represent the savings that would 
be realized if current smokers were to quit. For such individuals, much (but not all) of the damage has been done, whether or not they quit.

Second, our findings showing that public insurers bear a disproportionate share of the cost reflect the result that smokers were more likely to be covered by Medicare, Medicaid, and other government payers than were former smokers and those who had never smoked in this age cohort. Our methodology was based on the assumption that smoking causes increased government coverages. This assumption is plausibly the case for Medicare and Medicaid. Persons below age 65 only become eligible for Medicare for reasons of serious disability, although we cannot determine the fraction of cases of disability attributable to smoking or to some other cause. And serious illness and disability generally determines enrollment in Medicaid as well. Medicaid imposes stringent asset and income eligibility screens. A study using data on younger individuals that controlled for several other factors, including native intelligence, found that smoking reduced wages by roughly 5 to 8 percent (Levine et al. 1997). In our analysis, we controlled for household income, but not income accruing to the household member. Household income is the concept used by Medicaid for purposes of establishing eligibility, but a low-wage individual in this age cohort would have been more likely to leave the labor force and, holding family income constant, become eligible for Medicaid. In our analysis of effects of smoking, we also controlled for several other determinants of health insurance coverage, including education, marital status, gender (see, for example, Currie and Yelowitz 1999), race, problem drinking, body mass index, and risk tolerance, but not for native intelligence or cognition. Thus, we did account for many socioeconomic factors that are plausibly correlated with type of insurance coverage and smoking status.

For veterans' and military health insurance coverage, the situation is more complex. Historically, the U.S. military has greatly encouraged smoking by selling low-price cigarettes to soldiers (Tate 1999). For this and other reasons, including peer effects and lack of information on the deleterious health effects of smoking, many men in the military smoked, certainly in the age cohort we studied. In this sense, the fact that the U.S. government is bearing an extra burden attributable to smoking-related diseases seems equitable. On the other hand, eligibility for such health insurance coverage is not dependent on having a serious illness or disability. This fact makes it more likely that much of the cost would have been incurred even if the persons had never smoked. 
To learn more about this issue, it is useful to compare the marginal effect for the other government category for current plus former one to four years, 0.030, with the corresponding marginal effect for persons who quit smoking more than twenty years before Wave 1, 0.011 (see table 1.4). Relative to private group insurance coverage, the omitted reference group, the probability of having other government coverage was much higher for current plus one-to-four-year former smokers than for persons who quit smoking many years ago. We chose this comparison because the adverse health effects from smoking among persons who quit more than twenty years earlier were minimal. This comparison suggests that, even for other public health insurance coverage, the onset of adverse health leads to persons seeking coverage from these sources. But as with Medicare and Medicaid, there is reason to be cautious because our estimates of burden for the public payers, though plausibly higher than for private insurers, may be somewhat overstated. To the extent that individual health insurers either exact a premium surcharge or refuse to cover smokers, it is not surprising that smoking reduces the probability of having such coverage.

Our other caveats are more minor. Our cost estimates did not include the cost of drugs or nursing home admissions. The latter occurrences are extremely rare for persons in this age group, but nursing home stays are typically costly. We made no adjustments for technological change. There have been dramatic decreases in mortality from cardiovascular diseases in particular (Cutler and Meara 1998). To the extent that improvements in treating disease occur, we overestimate the cost of smoking. These improvements will be offset by secular increases in the unit cost of care. Also, changes in payment policy are unknown. Of course, if smoking becomes less costly, perhaps fewer smokers will decide to quit. Further, more youths may start the habit.

We applied only a crude adjustment for the cost of end-of-life care. In a survey like the Health and Retirement Study, which obtains data on the use of health services retrospectively, little information on decedents' use is available. Much more precise estimates of such cost can be obtained from insurance claims data.

We did not include other nonmedical costs of smoking, such as the cost of lost productivity and nonpecuniary losses associated with pain and suffering. Although these losses are important, both from private and social vantage points, our focus in this study was on medical cost and the distribution of such cost by source of payment for personal health services. 
In this study, we examined only smoking's influence on the cost of medical care during late middle age. Effects may differ appreciably by age cohort. It is plausible that effects on hospital and nursing home use are smaller for persons younger than age 51. Mortality effects are smaller than for persons aged 51 to 67 . For persons older than 67 , the effect on use of nursing home care is likely to be considerably larger. To the extent that there are more nursing home admissions, it will be possible to obtain more precise estimates of the effect of smoking.

Having acknowledged these caveats, we believe this study has (1) greatly improved the framework for gauging cost impacts of smoking and (2) established that the burdens of this habit are indeed substantial-in fact, for this age group, much more substantial than previous studies have reported. In our analysis, we accounted for many of the criticisms of past research on smoking cost used by experts for plaintiffs in tobacco litigation (see, for example, Rubin 1997 for a critique of such studies). Although smoking clearly is a cause of poor health, whether tobacco companies caused the damage or the harm is self-inflicted is a larger question that our study has not addressed.

\section{Note}

This research was supported in part by a grant from the National Institute on Aging to Duke University entitled "The Private and Social Cost of Smoking" (1R01-AG-16816).

\section{References}

Abraham, Kenneth S. (1986). Distributing Risk: Insurance, Legal Theory, and Public Policy. New Haven: Yale University Press.

Atkinson, A. B., and Joy L. Townsend (1977). "Economic Aspects of Reduced Smoking," The Lancet, Sept. 3, 492-494.

Barendregt, Jan J., Luc Bonneux, and Paul J. van der Maas (1997). “The Health Care Costs of Smoking," New England Journal of Medicine, Oct. 9; 337(15):1052-57.

Barsky, Robert B., et al. (1997). "Preference Parameters and Behavioral Heterogeneity: An Experimental Approach in the Health and Retirement Study," Quarterly Journal of Economics, May, 112(2):537-79.

Bartecchi, Carl E., Thomas D. MacKenzie, and Robert W. Schrier (1994). "The Human Costs of Tobacco Use" (First of Two Parts), New England Journal of Medicine, March 31, 33(13):907-12.

Currie, Janet, and Aaron Yelowitz (1999). "Health Insurance and Less Skilled Workers," National Bureau of Economic Research Working Paper 7291, August. 
Cutler, David M., and Ellen Meara (1998). "The Medical Costs of the Young and Old: A Forty-Year Old Perspective," in David Wise, Frontiers in the Economics of Aging. Chicago, IL: University of Chicago Press, 215-42.

Fry, Willard, Jerri Lynn Phillips, and Herman R. Menck (1999). “Ten-Year Survey of Lung Cancer Treatment and Survival in Hospitals in the United States," Cancer, Nov. 1, 86(9):1867-76.

Hanson, Jon D. and Kyle D. Logue (1998). "The Costs of Cigarettes: The Economic Case for Ex Post Incentive Regulation," Yale Law Journal 107(5), March: 1163-1361.

Harris, Jeffrey E. (1997). "Estimates of Smoking-Attributable Medicaid Expenditures in Florida," April 15.

Hasdai, David, Amir Lerman, Charanjit Rihal, Douglas A. Criger, Kirk N. Garratt, Amadeo Betriu, Harvey D. White, Eric J. Topel, Christopher B. Granger, Stephen G. Ellis, Robert M. Califf, and David R. Holmes (1999). "Smoking Status and Outcome After Primary Coronary Angioplasty for Acute Myocardial Infarction," American Heart Journal, 177(4):612-20.

Hausman, Jerry, Bronwyn H. Hall, and Zvi Griliches (1984). "Economic Models for Count Data with an Application to the Patent-R\&D Relationship," Econometrica, July, 52(4):909-38.

Hersch, Joni, and W. Kip Viscusi (1990). "Cigarette Smoking, Seatbelt Use, and Differences in Wage-Risk Tradeoffs," Journal of Human Resources, Spring 25(2):202-27.

Ho, Robert (1998). "The Intention to Give Up Smoking: Disease Versus Social Dimensions," The Journal of Social Psychology, 183(3):368-80.

Hodgson, Thomas A. (1992). "Cigarette Smoking and Lifetime Medical Expenditures," The Milbank Quarterly, 70(1):81-125.

Jacobson, Peter D., and Kenneth E. Warner (1999). "Litigation and Public Health Policymaking," Journal of Health Policy, Politics and Law, 24:769-804.

Jones, Andrew M. (1996). "Smoking Cessation and Health: A Response," Journal of Health Economics, 15:755-759.

Leu, Robert E., and Thomas Schaub (1985). "More on the Impact of Smoking on Medical Care Expenditures," Social Science and Medicine, 21(7):825-827.

Levine, Philip B., Tara A. Gustafson, and Ann D. Velenchik (1997). “More Bad News for Smokers: The Effects of Cigarette Smoking on Wages," Industrial and Labor Relations Review, 50(3):493-509.

Lubitz, James D., and Gerald F. Riley (1993). “Trends in Medicare Payments in the Last Year of Life," New England Journal of Medicine, April 15, 328(15):1092-96.

Manning, Willard G., Emmett B. Keeler, Joseph P. Newhouse, Elizabeth M. Sloss, and Jeffrey Wasserman (1989). "The Taxes of Sin: Do Smokers and Drinkers Pay Their Way?" Journal of the American Medical Association, 261:1604-09.

Manning, Willard G., Emmett B. Keeler, Joseph P. Newhouse, Elizabeth M. Sloss, and Jeffrey Wasserman (1991). The Cost of Poor Health Habits. Cambridge, MA: Harvard University Press.

Max, Wendy (1997). "Estimation of Smoking-Attributable Public Expenditures for the State of Texas, 1968-2007," July 3. 
Miller, Vincent P., Carla Ernst, and FranRois Collin (1999). "Smoking-Attributable Medical Care Costs in the USA," Social Science and Medicine, 48:375-91.

Miller, Vincent P., Caroline R. Jones, Carla Ernst, Franßois Collin (1997). “Smoking-Attributable Medical Care Costs: Models and Results," Berkeley Economic Research Associates, Berkeley, CA, Sept. 3.

MMWR Morbidity, Mortality, Weekly Report (1993). "Cigarette Smoking-Attributable Mortality and Years of Potential Life Cost-United States," August 27; 42(3):645-649.

Moore, Michael J., and James W. Hughes (2001). "The Health Care Consequences of Smoking and Its Regulation," Frontiers in Health Policy Research, Vol. 4: 31-76.

Oster, G., G. A. Colditz, and N. L. Kelly (1984). "The Economic Costs of Smoking and Benefits of Quitting for Individual Smokers," Preventive Medicine, 13(4):377-89.

Peto, Richard (1994). Mortality from Smoking in Developed Countries, 1950-2000: Indirect Estimates from National Vital Statistics. New York: Oxford University Press.

Rabin, Robert L. (1993). "Institutional and Historical Perspectives on Tobacco Tort Liability," in Robert L. Rabin and Stephen D. Sugarman, eds., Smoking Policy: Law, Politics and Culture. New York: Oxford University Press, 110-30.

Ramalingam, S., K. Pawlish, S. Gadgeel, R. Demers, and G. P. Kalemberian (1998). “Lung Cancer in Young Patients: Analysis of Surveillance, Epidemiology, and End Results Database," Journal of Clinical Oncology, February, 16(2):651-657.

Rubin, Donald B. (1997). "Texas Tobacco Litigation: Report of Professor Donald Rubin," August 27.

Tate, Cassandra (1999). Cigarette Wars: The Triumph of the Little White Slaver. New York: Oxford University Press.

U.S. Centers for Disease Control and Prevention (1999). “U.S. Life Tables 1997," National Vital Statistics Reports, Vol. 47, No. 8, December 13.

U.S. Department of Commerce, Statistical Abstract of the U.S., 1999. Washington, D.C.: Government Printing Office.

U.S. Department of Health and Human Services, Substance Abuse and Mental Health Services Administration. National Household Survey on Drug Abuse: Main Findings 1998. Rockville, MD.: National Clearinghouse for Alcohol and Drug Information, March 2000.

U.S. Environmental Protection Agency, The Costs and Benefits of Smoking Restrictions: An Assessment of the Smoke-Free Environment Act of 1993 (H.R. 3434). Indoor Air Division, Office of Radiation and Indoor Air. Washington, D.C.: U.S. Environmental Protection Agency, April 1994.

U.S. Physician Payment Review Commission, Annual Report to Congress, 1995. Washington, D.C.: The Commission.

U.S. Prospective Payment Assessment Commission, Medicare and the American Health Care System: Report to Congress. Washington, D.C.: The Commission, June 1995.

Viscusi, W. Kip (1995). "Cigarette Taxation and the Social Consequences of Smoking," in James Poterba, ed. Tax Policy and the Economy, Vol. 9. Cambridge, MA: MIT Press, 51-101. 
Viscusi, W. Kip (1999). "The Governmental Composition of the Insurance Costs of Smoking," Journal of Law and Economics, October, XLII(2):574-609.

Warner, Kenneth E., Frank J. Chaloupka, Philip J. Cook, Willard G. Manning, Joseph P. Newhouse, Thomas E. Novotny, Thomas E. Schelling, and Joy Townsend (1995). Tobacco Control, 4:380-386.

Warner, Kenneth E., Thomas A. Hodgson, and Caitlin E. Carroll (1999). “Medical Costs of Smoking in the United States: Estimates, Their Validity, and Their Implications," Tobacco Control. Autumn, 8(3):290-300.

Wray, Linda A., A. Regula Herzog, Robert J. Willis, and Robert B. Wallace (1998). "The Impact of Education and Heart Attack on Smoking Cessation Among Middle-Aged Adults," Journal of Health and Social Behavior, December:271-94. 
Copyright of NBER/Frontiers in Health Policy Research is the property of MIT Press and its content may not be copied or emailed to multiple sites or posted to a listserv without the copyright holder's express written permission. However, users may print, download, or email articles for individual use. 